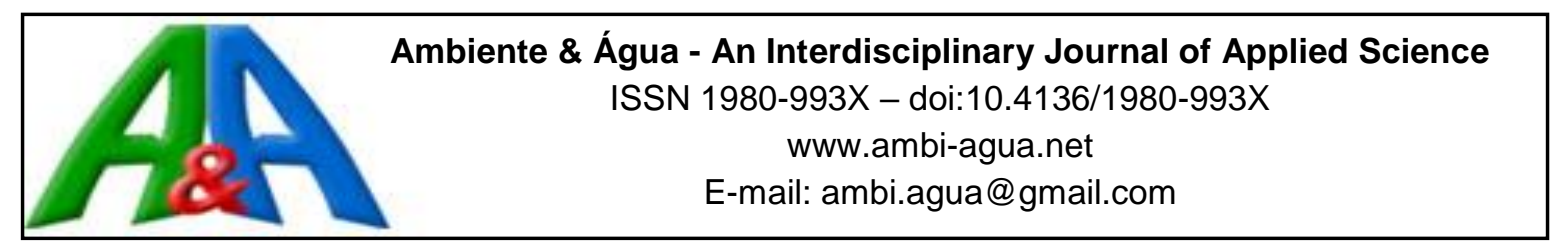

\title{
Caracterização hidroambiental de nascentes
}

\author{
doi:10.4136/ambi-agua.1909 \\ Received: 01 Apr. 2016; Accepted: 19 Oct. 2016 \\ Mariana Santos Leal ${ }^{1 *}$; Kelly Cristina Tonello ${ }^{1}$; \\ Herly Carlos Teixeira Dias ${ }^{2}$; Rafael Mingoti ${ }^{3}$ \\ ${ }^{1}$ Universidade Federal de São Carlos (UFSCAR), Sorocaba, SP, Brasil \\ Programa de Pós-graduação em Planejamento e Uso dos Recursos Renováveis (PPGPUR) \\ ${ }^{2}$ Universidade Federal de Viçosa (UFV), Viçosa, MG, Brasil \\ Departamento de Engenharia Florestal \\ ${ }^{3}$ Empresa Brasileira de Pesquisa Agropecuária (EMBRAPA), Campinas, SP, Brasil \\ Departamento de Gestão territorial \\ *Autor correspondente: e-mail: mari_floresta@hotmail.com, \\ kellytonello@ufscar.br, herly@ufv.br, rafael.mingoti@embrapa.br
}

\section{RESUMO}

As nascentes consistem em um afloramento do lençol freático que dão origem aos fluxos d'água. Essas águas passam a formar a rede de drenagem. Os impactos ambientais negativos, provocados em qualquer porção da bacia podem interferir na quantidade e qualidade da água e, dependendo do impacto, formas ou alternativas diferentes de manejo deverão ser implantadas visando à melhoria do ambiente. Este trabalho teve por objetivo a caracterização das nascentes da bacia do córrego Itanguá, Capão Bonito, SP, Brasil, quanto ao tipo e estado de conservação, assim como a identificação de impactos ambientais negativos presentes. Quanto ao tipo, as nascentes foram classificadas em pontual ou difusa, e o estado de conservação obtido por meio da avaliação macroscópica foi ranqueado em ótimo, bom, razoável, ruim e péssimo. Na bacia foram identificadas 19 nascentes e, das 15 que foram visitadas, nove foram classificadas como pontuais, enquanto que seis foram difusas. Quanto ao estado de conservação, duas foram classificadas como ótimas, 12 como boas e uma como razoável. Também a partir da avaliação macroscópica foi observado que a presença de espécies exóticas, tanto animal (Sus scrofa) como vegetal (Pinus spp.), e a ausência de vegetação nativa na área de preservação permanente foram os impactos ambientais negativos mais frequentes. A metodologia empregada se mostrou eficiente como análise qualitativa visual da situação das nascentes e como fornecedoras de informação para subsidiar ações para a conservação da água na Floresta Nacional de Capão Bonito, SP, Brasil.

Palavras-chave: avaliação macroscópica, conservação da água, Sus scrofa.

\section{Hydroenvironmental characterization of springs}

\section{ABSTRACT}

Springs consist of an upwelling of groundwater from which water flows. This water then forms the drainage network. The negative environmental impacts caused in any portion of the basin may affect the quantity and quality of water. This study characterized the springs of Itanguá watershed, Capão Bonito, SP, considering their types, their conservation status, and 
the presence of negative environmental impacts. As for the type, springs were classified as "point" or "diffuse" and, regarding conservation status, they were ranked as "excellent", "good", "fair", "bad" and "very bad" based on macroscopic evaluation. Nineteen springs were identified and 15 visited; of these, nine were classified as "point", and six as "diffuse." With respect to conservation status, two springs were classified as "excellent", 12 as "good", and one as "fair". The presence of exotic species was observed by macroscopic evaluation, such as animal (boar) and vegetation (Pinus spp.). The lack of vegetation in "permanent preservation areas" was the most frequently observed environmental impact found. The methods used were efficient as a first analysis of the situation of the springs and to provide information to support programs to improve water conservation in the Floresta Nacional de Capão Bonito, SP.

Keywords: macroscopic evaluation, Sus scrofa, water conservation.

\section{INTRODUÇÃO}

As nascentes consistem em um afloramento do lençol freático que dão origem aos fluxos d'água formadores da rede de drenagem. Porém, para a nascente ser considerada ideal, ela deve fornecer água de boa qualidade de maneira abundante e contínua, com boa distribuição no tempo e onde a variação da vazão tenha um mínimo adequado ao longo do ano (Calheiros et al., 2009).

A área de preservação permanente (APP), que se constitui em área protegida com a função ambiental de preservar a estabilidade geológica, a paisagem, a biodiversidade, facilitar o fluxo gênico de fauna e flora, proteger o solo e assegurar o bem-estar das populações humanas, são também indispensáveis na preservação dos recursos hídricos (Brasil, 2012). Devido a essa tamanha importância, sua preservação é prevista na Lei federal $n^{\circ}$. 12.651/12 (Código Florestal), segundo a qual as áreas ao redor das nascentes, num raio mínimo de 50 metros, devem ser ocupadas por vegetação nativa e mantidas preservadas.

As unidades de conservação (UC), tanto as de proteção integral quanto as de uso sustentável, apresentam, como um de seus objetivos, a proteção dos recursos hídricos indo ao encontro dessa necessidade de preservar não só esses recursos, como também as áreas com vegetação nativa em toda a bacia (Brasil, 2000).

Um subsídio importante à gestão das bacias é a identificação dos impactos negativos presentes, pois dependendo do impacto, formas ou alternativas diferentes de manejo deverão ser implantadas visando à melhoria do ambiente. Situações, por exemplo, em que há impactos relacionados à poluição sanitária promoverão alterações da qualidade da água, enquanto que impermeabilização e/ou compactação do solo acarretam uma diminuição da infiltração de água no solo. A ausência de proteção ao redor das nascentes também pode facilitar o fluxo de pessoas e animais, ocasionando o pisoteio e por consequência, alteração na vazão das nascentes.

A avaliação macroscópica das nascentes, considerada por Felippe e Magalhães Junior (2012) uma metodologia simples, prática, didática e com resultados satisfatórios, tem o objetivo de verificar de forma qualitativa e visual o grau de conservação em que as nascentes se encontram a partir da identificação dos impactos ambientais negativos presentes, para que possam ser mitigados.

Os resultados gerados neste estudo são informações importantes ao plano de manejo da Flona de Capão Bonito, principal instrumento de gestão das áreas protegidas, mas que infelizmente encontra-se obsoleto e necessitando de revisão.

Dessa forma, este trabalho teve por objetivo a caracterização das nascentes da bacia do córrego Itanguá, quanto ao tipo e grau de conservação, assim como a identificação de 
impactos ambientais negativos presentes de modo a subsidiar ações que proporcionem a conservação da água na Floresta Nacional de Capão Bonito, SP, Brasil.

\section{MATERIAL E MÉTODOS}

\section{1. Área de estudo}

A bacia do córrego Itanguá está localizada no município de Capão Bonito, estado de São Paulo, Brasil, entre as coordenadas $23^{\circ} 54^{\prime}$ e $23^{\circ} 59^{\prime} \mathrm{S}$; $48^{\circ} 30^{\prime}$ e $48^{\circ} 32^{\prime} \mathrm{W}$. Grande parte de sua área está inserida na Floresta Nacional de Capão Bonito, localizada entre as latitudes $23^{\circ} 50^{\prime}$ e $24^{\circ} 00^{\prime} \mathrm{S}$ e longitude $48^{\circ} 20^{\prime}$ e $48^{\circ} 40^{\prime} \mathrm{O}$, entre os municípios de Capão Bonito e Buri, região do Vale da Serra do Paranapiacaba, sudoeste do estado (Figura 1).

Sua vegetação é composta por Floresta Ombrófila Densa e Savana (SOS Mata Atlântica; INPE, 2012). A altitude média é de 700 metros, com relevo levemente ondulado e o clima da região é caracterizado como Cwa segundo a classificação de Koeppen e precipitação média anual de $1200 \mathrm{~mm}$ (Cepagri, 2015).

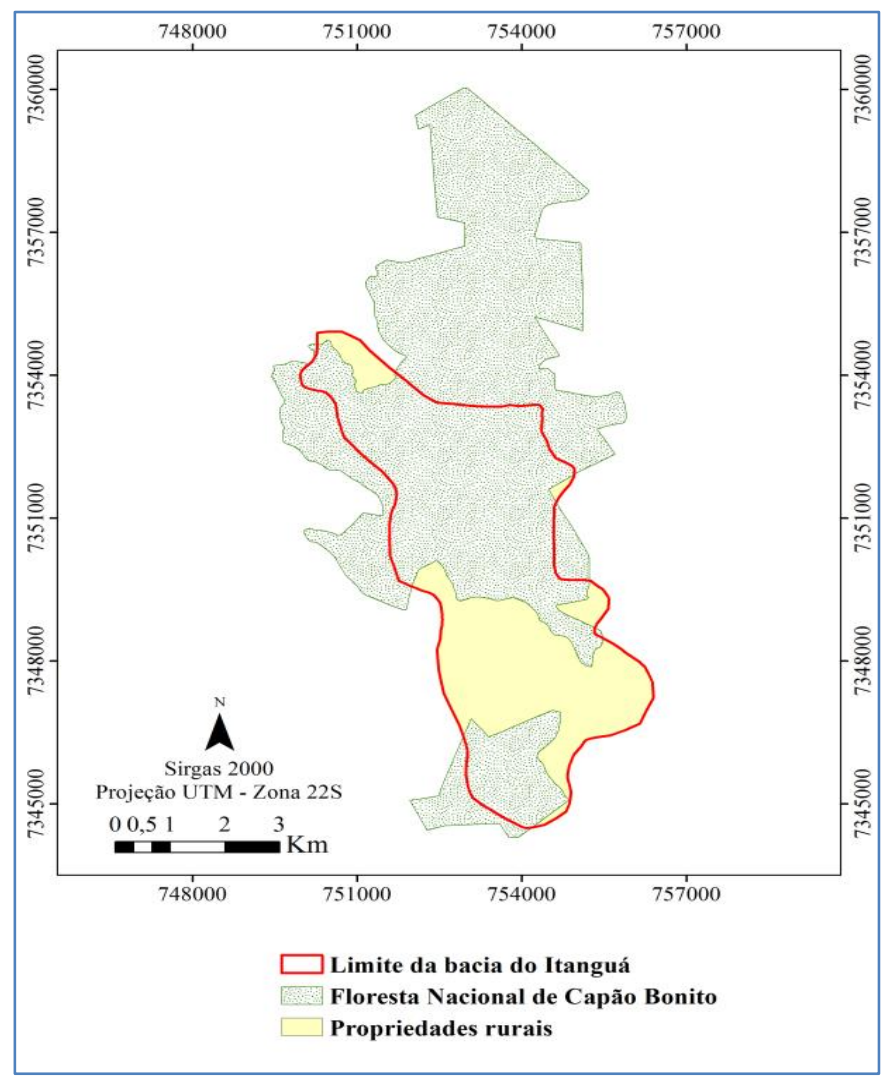

Figura 1. Localização da Floresta Nacional de Capão Bonito e da bacia do Itanguá, Capão Bonito, SP, Brasil.

A Flona de Capão Bonito possui mais de $50 \%$ de seu território ocupado por plantios de Pinus spp., com idade aproximada de 50 anos. Dos 4.344 hectares de área, 3.489,39 ha são ocupados por reflorestamentos, distribuídos em: 2.402,19 ha de Pinus elliotti; 39,47 ha de Pinus spp.; 1.002,00 ha de Araucaria angustifolia; 45,73 ha de experimentos com várias outras espécies florestais nativas e exóticas e outros 270 ha de mata nativa. A área restante é ocupada por aceiros, estradas, espaço para edificações e áreas de lazer (Brasil, 2015). A Flona está dividida em duas glebas, e $40 \%$ de sua área total está inserida na bacia do córrego Itanguá. 


\subsection{Caracterização das nascentes quanto ao tipo}

A bacia foi visitada durante os meses de dezembro/2014 a fevereiro/2015, contemplando assim a estação chuvosa. As nascentes foram georreferenciadas com um receptor GPS de navegação Garmin eTrex Vista e analisadas in loco. A espacialização e análise das informações, tanto as coletadas em campo quanto as obtidas nas cartas topográficas de Buri (SF-22-Z-D-V-4) e Itanguá (SF-22-Z-D-VI-3) do Instituto Brasileiro de Geografia e Estatística (IBGE), foram realizadas no programa QGIS 2.8 e ArcMap 10.1.

As nascentes foram então classificadas quanto ao seu tipo, podendo ser pontual quando apresentava um fluxo d'água em um único ponto do terreno, ou difusa quando havia fluxo d'água em vários pontos (Castro, 2007). A classificação quanto à persistência de fluxo e a quantificação da vazão das nascentes não puderam ser realizadas devido à ausência de quantidade de água necessária para tais aferições.

\subsection{Avaliação macroscópica}

Para a identificação dos impactos ambientais das nascentes da bacia, qualitativamente, foi realizada uma avaliação macroscópica, onde os parâmetros foram adaptados de acordo com as necessidades presentes neste trabalho, tendo como base as metodologias propostas por Gomes et al. (2005) e Felippe e Magalhães Junior (2012). Estes autores usaram como base o Guia de Avaliação da Qualidade das Águas (2004) e a Classificação do grau de impacto da nascente (2004).

A avaliação utilizou os parâmetros especificados na Tabela 1, os quais foram classificados em bom, médio e ruim a partir da atribuição de um valor de um a três, de acordo com a qualificação que cada um recebeu. Assim, a pontuação varia de 11 pontos - quando todos os parâmetros são considerados ruins - a 33 pontos - no caso de todos os parâmetros serem bons.

Tabela 1. Parâmetros utilizados na avaliação macroscópica de nascentes.

\begin{tabular}{lccc}
\hline \multirow{2}{*}{ Parâmetro } & \multicolumn{3}{c}{ Qualificação } \\
\cline { 2 - 4 } & Ruim (1 ponto) & Médio (2 pontos) & Bom (3 pontos) \\
\hline Lixo & Muito & Pouco & Ausente \\
Materiais flutuantes & Muito & Pouco & Ausente \\
Espumas & Muito & Pouco & Ausente \\
Óleos & Muito & Pouco & Ausente \\
Esgoto & Presença & Evidências & Ausente \\
Vegetação na APP & Ausente & Exótica & Nativa \\
Uso pela fauna & Presença & Evidências & Ausente \\
Uso antrópico & Presença & Evidências & Ausente \\
Proteção (cerca) & Ausente & Presente, mas com & Presente, mas com \\
Áreas construídas & Menos de 50 metros & Entre 50 e 100 metros & Acima de 100 metros \\
Tipo da área de & Informação ausente & Propriedade privada & Área protegida \\
inserção &
\end{tabular}

Fonte: Adaptada de Gomes et al. (2005) e Felippe e Magalhães Junior (2012).

Após a contabilização (soma) dos pontos da avaliação, as nascentes foram classificadas quanto ao grau de conservação em relação aos impactos presentes: Classe A (ótimo - 31 a 33 pontos), Classe B (bom - 28 a 30 pontos), Classe C (razoável - 25 a 27 pontos) e Classe E (péssimo - abaixo de 22 pontos) (Gomes et al., 2005; Felippe e Magalhães Junior, 2012). 


\section{RESULTADOS E DISCUSSÃO}

\subsection{Caracterização das nascentes quanto ao tipo}

$\mathrm{Na}$ bacia do Itanguá foram identificadas 19 nascentes, sendo 12 localizadas dentro da Floresta Nacional de Capão Bonito e as demais nas propriedades rurais do entorno. Do total, três não constam nas cartas topográficas utilizadas, mas foram visualizadas em campo $(6,8 \mathrm{e}$ 9).

Quatro nascentes não puderam ser visitadas em decorrência da dificuldade de acesso ao local, portanto somente 15 puderam ser avaliadas in loco. Dessas, nove foram classificadas como pontuais enquanto que seis foram difusas (Figura 2a).

\subsection{Avaliação macroscópica}

Nenhuma nascente apresentou pontuação máxima, porém todas apresentaram pontuação superior a 25, não existindo nenhuma nascente com qualificação ruim (D) ou péssima (E). $O$ menor valor (27) foi verificado na nascente 7, enquanto que as nascentes 5 e 6 obtiveram a maior pontuação (31) (Figura 2b).

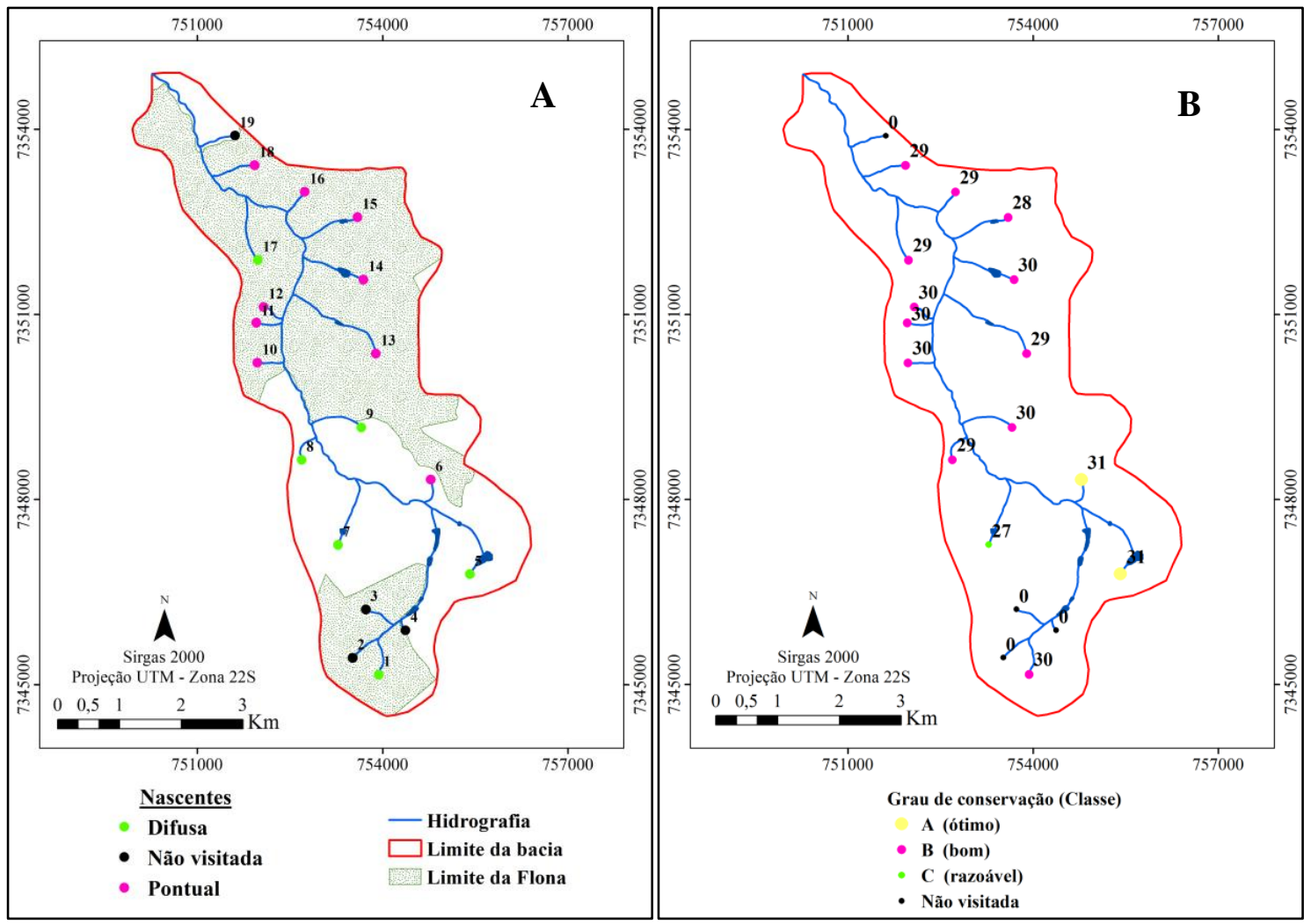

Figura 2. (a) Localização das nascentes da bacia do Itanguá e a classificação quanto ao tipo;

(b) pontuação e grau de conservação das nascentes da bacia do Itanguá.

Todos os parâmetros foram analisados e apresentaram as seguintes considerações:

- Lixo, Materiais flutuantes, Espumas, Óleos, Esgoto: nenhum desses materiais foi encontrado em nenhuma das nascentes avaliadas. Mesmo nas nascentes com fácil acesso não houve nenhum indício de lixo nem de poluição sanitária. Esses resultados indicam menor probabilidade de contaminação, fato este que só pode ser comprovado a partir de uma análise química da qualidade da água.

- Vegetação: 60\% das nascentes apresentaram vegetação exótica (Pinus spp.) predominante na área de preservação permanente, enquanto que em $27 \%$ havia predominância 
de vegetação nativa e somente $13 \%$ estavam com solo descoberto.

- Uso pela fauna e antrópico: em 46,7\% das nascentes foi constatado o uso por animais. Em seis delas havia evidência de uso por Javali, espécie facilmente encontrada na região e que vem causando vários impactos no ambiente. Nas demais nascentes, havia evidência de pisoteio pelo gado, contudo não foi encontrado nenhum animal no momento da avaliação. Esse uso pelos animais pode acarretar em contaminação da água por fezes e urina. Todas as nascentes com presença de pegadas de javali estão localizadas dentro da Flona. Verificou-se também o uso antrópico em apenas uma nascente relacionado ao uso por animais, já que a evidência encontrada foi a presença de ceva na nascente, local apreciado pelo javali.

- Proteção: a proteção da área com cercas é uma prática importante em termos de conservação da área, pois pode impedir o acesso às nascentes, tanto de animais quanto de pessoas, evitando assim que a degradação ocorra. Todas as nascentes que se encontravam dentro da área da unidade de conservação não apresentavam cerca ao redor, mas já se encontram em uma área protegida por lei.

- Áreas construídas: quanto mais próximas as nascentes estão das áreas edificadas, maior a probabilidade de impactos antrópicos. No entanto nenhuma nascente apresentou construções a menos de 100 metros de distância, fato corroborado pela ausência de lixo, esgoto, óleos e materiais flutuantes nas nascentes.

- Tipo da área de inserção: 66\% das nascentes avaliadas se encontram dentro da área da unidade de conservação.

A partir da análise dos dados pôde-se perceber, portanto, que os maiores impactos encontrados nas áreas das nascentes foram a presença de espécies exóticas, tanto animal, a qual pode provocar a contaminação da água (fezes e urina), pisoteio e revolvimento do solo, quanto a vegetal, por ocupar as áreas de preservação permanente destinadas à vegetação nativa e, assim, poder alterar o ciclo hidrológico e a regeneração natural no sub-bosque.

Os javalis (Sus scrofa) e os "javaporcos" (híbridos férteis) são altamente competitivos com as espécies nativas, pois são espécies agressivas e resistentes sem predadores naturais, impactando o ambiente por onde passam, revolvendo o solo, destruindo a vegetação nativa devido ao pisoteio e alimentação, e provocando até mesmo a desestruturação do solo, podendo desencadear processos erosivos e de assoreamento dos corpos d'água, sem contar os prejuízos econômicos das lavouras (Massei e Genov, 2004).

No mundo todo é possível encontrar casos de distúrbios provocados pelos javalis. Mitchell (2011) verificou significantes impactos na qualidade da água em áreas tropicais alagadas na Austrália. Em um estudo realizado na Nova Zelândia foi identificada a perturbação direta pelos suínos selvagens através da retirada de plantas, e indiretamente pelo aumento de nitrato, provocando alterações no ambiente (Krull et al., 2013).

No Brasil a presença de grupos de javalis asselvajados já foi registrada em vários estados, como Rio Grande do Sul, Santa Catarina, Paraná, São Paulo, Minas Gerais, Mato Grosso do Sul, Mato Grosso, Goiás, Bahia e Acre (IBAMA, 2015). Segundo os anexos do $1^{\circ}$ Relatório do grupo técnico sobre espécies exóticas com potencial de invasão, o município de Capão Bonito está na lista dos 64 municípios com registro de javali no estado de São Paulo (São Paulo, 2013).

Em um estudo realizado na região sul do Brasil, os resultados mostraram a preferência da espécie por áreas naturais preservadas, representando uma grande ameaça para as florestas e áreas protegidas dessa região. Os autores também sugerem mais estudos quanto ao impacto da espécie sobre os ambientes naturais, principalmente o impacto provocado pela predação de sementes de Araucária (Araucaria angustifolia), espécie arbórea presente na Flona e que 
acaba se comportando como fornecedora de alimento e facilitando assim a presença dos animais no local (Hegel e Marini, 2013).

Esses animais têm atraído a atenção de governos e pesquisadores por ser considerada uma das piores espécies exóticas invasoras (Lowe et al., 2000). No Brasil, em razão do crescimento populacional e dispersão sem controle dos javalis em todo o país, a Instrução Normativa $\mathrm{n}^{\circ} .03$ (Brasil, 2013) autoriza o controle populacional do javali que vive em liberdade em todo o território nacional. Outro tipo de controle apontado em estudos é a colocação de cercas, que pode ajudar, dependendo de cada caso (Mitchell, 2011).

Para o controle do javali, a caça na região da Flona já tem ocorrido e, segundo funcionários e moradores da região, o avistamento desses animais já diminuiu. A construção de cercas ao redor das nascentes evitaria o acesso desses e de até mesmo outras espécies animais, evitando degradação.

O gênero Pinus spp. foi introduzido na UC para a realização de experimentos devido à política de reflorestamento em larga escala que estava sendo incentivada no país na década de 60, restando uma grande quantidade de talhões em pé até hoje.

Como a Flona é uma UC de uso sustentável, o plantio de espécies exóticas como o Pinus é permitido, porém elas não devem estar presentes nas áreas de preservação permanente, margeando os cursos d'água e as nascentes (Brasil, 2012).

O Pinus, além de ser exótico, é também considerado uma espécie invasora em ambientes naturais, pois apresenta elevado consumo de água quando plantado de maneira adensada, além de poder impedir a regeneração natural. Porém, ele também pode promover benefícios em determinadas circunstâncias atuando como facilitador, como pode ser visto em alguns casos citados a seguir.

Onaindia et al. (2013) verificou que a regeneração natural no sub-bosque de um plantio antigo de Pinus radiata, espécie exótica, no Norte da Península Ibérica apresentou composição pouco semelhante à floresta nativa, sendo necessário algum manejo para o avanço do processo sucessional.

No Brasil, em um estudo realizado em uma região de Cerrado, no município de Assis, SP, Durigan et al. (2014) perceberam que o plantio de Pinus elliottii, independente do espaçamento, acelerou cerca de quatro vezes a cobertura do terreno em relação à área testemunha sem plantio. Porém, a densidade de plantas em regeneração tem sido menor nos últimos anos, indicando que a remoção gradual dos indivíduos poderia ser favorável. No entanto, os autores advertem que são necessários mais estudos a longo prazo em relação à competição da espécie exótica com as nativas, sendo insuficiente os seis anos de observação.

Em um estudo já realizado na Flona de Capão Bonito pôde-se verificar a presença de indivíduos regenerantes (CAP $\geq 15 \mathrm{~cm}$ ) sob plantios de Pinus elliottii distribuídos em 38 espécies e 20 famílias, numa densidade de 600 ind/ha (Tonello, 2013), enquanto que em outros talhões é possível perceber a ausência de regeneração natural no sub-bosque.

O Pinus também pode influenciar, além da vegetação, a dinâmica hídrica da bacia. Em um estudo realizado por Swank e Douglas (1975), eles verificaram uma diminuição na produção de água de aproximadamente $94 \mathrm{~mm}$ em uma floresta plantada de Pinus strobus, com idade de 10 anos em relação à floresta natural.

Em uma bacia da África do Sul, onde a vegetação natural foi substituída por Eucalyptus grandis e Pinus patula, foi observada uma redução de $30 \%$ no deflúvio a partir do terceiro ano de implantação (Scott e Lesch, 1997). No entanto, Lima e Freire (1976) ao estudarem áreas com eucalipto, pinheiros e vegetação herbácea natural, situadas à margem do Córrego Monte Olimpo em Piracicaba, SP, não detectaram nenhuma consequência adversa sobre o regime da água do solo como consequência do reflorestamento.

Dessa forma, os resultados aqui apresentados podem subsidiar a gestão ambiental da Flona e do entorno, podendo ser voltada, principalmente, para a substituição das espécies 
exóticas florestais por espécies nativas nas áreas de mata ciliar. No entanto, o manejo dessas espécies deve ser planejado de acordo com o comportamento das mesmas no local, ou seja, é importante observar se ela está atuando como facilitadora ou não, já que as duas situações podem ser encontradas no local.

A colheita florestal, atividade que inicia esse processo de substituição de espécies, pode acarretar em significativos impactos negativos na bacia hidrográfica, como a alteração do balanço hídrico, da vazão e da concentração de nutrientes na água, como pode ser visto no estudo realizado por Oki (2002), onde a autora verificou um aumento na concentração de sedimentos na água devido ao maior escoamento superficial após o corte raso de uma floresta de Pinus. Por isso a exploração deve ser bem planejada em áreas com maiores declives e próximas aos cursos d'agua, como as de matas ciliares, para minimizar os impactos.

Nas áreas em que a substituição do pinus não é exigida pela lei, o manejo deve ser adequado, realizando-se desbastes, por exemplo. Já foi verificado que após a realização de um desbaste leve em povoamentos de Pinus sp., houve a redução do consumo de água em $75 \%$ em comparação com uma floresta não desbastada (Lima, 1979). No entanto esses valores podem variar de acordo com as características de cada local. No caso das nascentes que se encontram sem vegetação ou com outros tipos de uso, é necessário que elas sejam restauradas por meio de plantio de espécies nativas.

\section{CONCLUSÃO}

Das nascentes analisadas in loco, $60 \%$ foram caracterizadas como pontuais, enquanto que as demais foram difusas e, de acordo com a avaliação macroscópica, 13\% das nascentes foram consideradas com ótimo, $80 \%$ com bom e $7 \%$ com razoável estado de conservação.

Os principais impactos ambientais negativos observados foram a presença de espécies exóticas, tanto animal como vegetal: Javali (Sus scrofa) e Pinus spp., e a ausência de vegetação nativa na área de preservação permanente dos cursos d'água.

A metodologia empregada foi considerada de fácil entendimento e utilização, apesar da avaliação de alguns parâmetros, como lixo, materiais flutuantes, espumas e óleos não fazer uso de valores numéricos para quantificá-los, visto que são difíceis de serem mensurados devido a uma grande variação de região para região. Ainda assim, se mostrou eficiente como uma análise qualitativa visual da situação das nascentes e como fornecedora de informações importantes no direcionamento do manejo a ser seguido para o controle dos impactos ambientais negativos. Esse tipo de conhecimento se constitui em importante etapa da gestão e planejamento de bacias hidrográficas.

\section{AGRADECIMENTOS}

À Coordenação de Aperfeiçoamento de Pessoal de Nível Superior (CAPES), pela bolsa de mestrado da primeira autora.

\section{REFERÊNCIAS}

BRASIL. Lei federal $n^{\circ} 9.985$, de 18 de julho de 2000, regulamenta o art. 225, §1o, incisos I, II, III e VII da Constituição Federal, institui o Sistema Nacional de Unidades de Conservação da Natureza (SNUC) e dá outras providências. Diário Oficial [da] União, Brasília, 19 jul. 2000. 
BRASIL. Lei federal $n^{\circ}$. 12.651, de 25 de maio de 2012, dispõe sobre a proteção da vegetação nativa; altera as Leis $\mathrm{n}^{\mathrm{os}} 6.938$, de 31 de agosto de 1981, 9.393, de 19 de dezembro de 1996, e 11.428, de 22 de dezembro de 2006; revoga as Leis $\mathrm{n}^{\mathrm{os}} 4.771$, de 15 de setembro de 1965, e 7.754, de 14 de abril de 1989, e a Medida Provisória n-2.166-67, de 24 de agosto de 2001; e dá outras providências. Diário Oficial [da] União, Brasília, 28 maio 2012.

BRASIL. Ministério do Meio Ambiente. Secretaria de Biodiversidade e Florestas. Departamento de Áreas Protegidas. Cadastro nacional de unidades de conservação CNUC. Unidade de conservação: Floresta nacional de Capão Bonito. Disponível: https://goo.gl/PMgYkG. Acesso em: 03 jun. 2015.

CALHEIROS, R. O. et al. Cadernos da Mata Ciliar n. 1: preservação e recuperação das nascentes, de água e vida. São Paulo: SMA, 2009. 35 p.

CASTRO, P. S. Recuperação e conservação de nascentes. Viçosa, MG: CPT, 2007. 272 p.

CENTRO DE PESQUISAS METEREOLÓGICAS E CLIMÁTICAS APLICADAS A AGRICULTURA - CEPAGRI. Clima dos municípios paulistas: Capão Bonito. Disponível em: https://goo.gl/FXXbQM. Acesso em: 03 jun. 2015.

DURIGAN, G.; CONTIERI, W. A.; MELO, A. C. G.; GARRIDO, M. A. O. Regeneração da mata ciliar sob plantio de Pinus elliotti var. elliotti em diferentes densidades. In: VILAS BÔAS, O.; DURIGAN, G. Pesquisas em conservação e recuperação ambiental no oeste paulista. São Paulo: Instituto Florestal, 2014. Disponível em: https://goo.gl/LJTD5A. Acesso em: 25 jun. 2015.

FELIPPE, M. F.; MAGALHÃES JUNIOR, A. P. Impactos ambientais macroscópicos e qualidade das águas em nascentes de parques municipais em Belo Horizonte - MG. Geografias, v. 8, n. 2, p. 8-23, 2012.

GOMES, P. M.; MELO, C.; VALE, V. S. Avaliação dos impactos ambientais em nascentes na cidade de Uberlândia-MG: análise macroscópica. Sociedade \& Natureza, v. 17, n. 32, p. 103-120, 2005.

HEGEL, C. G. Z.; MARINI, M. A. Impacto do javali europeu, Sus scrofa, em um fragmento da Mata Atlântica brasileira. Neotropical Biology and Conservation, v. 8, n. 1, p. 1724, 2013. http://dx.doi.org/10.4013/nbc.2013.81.03

INSTITUTO BRASILEIRO DO MEIO AMBIENTE E DOS RECURSOS NATURAIS RENOVÁVEIS - IBAMA. Instrução normativa $n^{\circ}$. 03, de 31 de janeiro de 2013. Decreta a nocividade do Javali e dispõe sobre o seu manejo e controle. Diário Oficial [da] União, Brasília, 01 fev. 2013, Seção 1, p. 88-89.

INSTITUTO BRASILEIRO DO MEIO AMBIENTE E DOS RECURSOS NATURAIS RENOVÁVEIS - IBAMA. O javali asselvajado: norma e medidas de controle. Disponível em: https://goo.gl/XcUnXD. Acesso em: 20 jun. 2015.

KRULL, C. R.; CHOQUENOT, D.; BURNS, B. R.; STANLEY, M. C. Feral pigs in a temperate rainforest ecosystem: disturbance and ecological impacts. Biological Invasions, v. 15, p. 2193-2204, 2013. http://dx.doi.org/10.1007/s10530-013-0444-9

LIMA, W.P. A água do solo e o crescimento da floresta. Piracicaba: IPEF, 1979. (Circular técnica, 59). 
LIMA, W. P.; FREIRE, O. Evapotranspiração em plantações de eucalipto e de pinheiro e em vegetação herbácea natural. IPEF, v. 13, p. 75-90, 1976.

LOWE, S.; BROWNE, M.; BOUDJELAS, S.; DEPOORTER, M. 100 of the World's worst invasive Alien species: a selection from the global invasive species database. Auckland: ISSG, 2000. 12 p.

MASSEI, G.; GENOV, P.V. The environmental impact of wild boar. Galemys, v. 16, n. especial, p. 135-145, 2004.

MITCHELL, J. Ecological impacts of feral pigs (Sus scrofa) on freshwater ecosystems in tropical Australia. In: EUROPEAN VERTEBRATE PEST MANAGEMENT CONFERENCE, 8., 26-30 set. 2011, Berlin. Julius-Kühn-Archiv, n. 432, 2011.

ONAINDIA, M.; AMETZAGA-ARREGI, I.; SAN SEBASTIAN, M.; MITXELENA, A.; RODRIGUEZ-LOINAZ, G.; PEÑA, L. et al. Can understorey native woodland plant species regenerate under exotic pine plantations using natural succession? Forest Ecology and Management, v. 308, p. 136-144, 2013. http://dx.doi.org/10.1016/j.foreco.2013.07.046

OKI, V. K. Impactos da colheita de Pinus taeda sobre o balanço hídrico, a qualidade da água e a ciclagem de nutrientes em microbacias. 2002. $71 \mathrm{f}$. Dissertação (Mestrado em Ciências Florestais) - Escola Superior de Agricultura Luiz de Queiroz, Universidade de São Paulo, Piracicaba, 2002.

SÃO PAULO (Estado). Secretaria do Meio Ambiente. Coordenadoria de Biodiversidade e Recursos Naturais. Anexos do $\mathbf{1}^{\mathbf{0}}$ relatório do grupo técnico sobre espécies exóticas com potencial de invasão. Dez. 2013. Disponível em: https://goo.gl/7n0RTd. Acesso em: 20 jun. 2015.

SCOTT, D. F.; LESCH, W. Streamflow responses to afforestation with Eucalyptus grandis and Pinus patula and to felling in the Mokobulaan experimental catchments, South África. Journal of Hydrology, v. 199, n. 3/4, p. 360-377, 1997. http://dx.doi.org/10.1016/S0022-1694(96)03336-7

SOS MATA ATLÂNTICA; INSTITUTO DE PESQUISAS ESPACIAIS - INPE. Atlas dos remanescentes da mata Atlântica. 2012. Disponível em: http://mapas.sosma.org.br/. Acesso em: 16 abr. 2015.

SWANK, W. T.; DOUGLAS, J. E. Conversion of hardwood-covered watershed to White Pine reduces water yield. Water Resources Research, v. 4, p. 947-954, 1975. http://dx.doi.org/10.1029/WR004i005p00947

TONELLO, K. C. Avaliação da regeneração natural em sub-bosque de plantios de Pinus elliottii Engelm. e Araucaria angustifolia (Bertol.) Kuntze em Capão Bonito - SP. 2013. 23 f. Iniciação Científica (Graduando em Engenharia Ambiental) - Universidade Federal de São Carlos, Sorocaba, 2013. 